\title{
Faktor yang Mempengaruhi Pendapatan Keluarga Miskin di Kecamatan Maesan Kabupaten Bondowoso
}

\author{
(Factors that Affecting Income of Poor Families \\ in District Maesan Bondowoso)
}

\author{
Dewa Murti, Moehammad Fathorrazi, Fivien Muslihatinningsih ${ }^{1}$ \\ Jurusan Ilmu Ekonomi Studi Pembangunan, Fakultas Ekonomi Dan Bisnis, Universitas Jember (UNEJ) \\ Jln. Kalimantan 37, Jember 68121 \\ Email: hudanur507@gmail.com
}

\begin{abstract}
Abstrak
Penelitian ini bertujuan untuk mengetahui faktor yang mempengaruhi pendapatan pada keluarga miskin di Kecamatan Maesan Kabupaten Bondowoso dengan menggunakan metode analisis Regresi Linier Berganda (Multiplier Regression Model). Data yang digunakan dalam penelitian ini adalah data primer yang berasal dari metode wawancara, metode kuisioner, metode observasi (cross section) dengan wilayah penelitian di Kecamatan Maesan Kabupaten Bondowoso. Hasil regresi yang diperoleh dari penelitian ini menunjukkan bahwa pendidikan $\left(\mathrm{X}_{1}\right)$ dan usia $\left(\mathrm{X}_{2}\right)$ berpengaruh positif terhadap pendapatan. Jumlah tanggungan keluarga $\left(\mathrm{X}_{3}\right)$ dan Jenis pekerjaan $\left(\mathrm{X}_{4}\right)$ berpengaruh negatif terhadap pendapatan. Nilai probabilitas dari masing-masing variabel bebas yaitu pendidikan $\left(\mathrm{X}_{1}\right)$ sebesar 0,0000 , usia $\left(\mathrm{X}_{2}\right)$ sebesar 0.0000 , jumlah tanggungan keluarga $\left(\mathrm{X}_{3}\right)$ sebesar 0.0000 dan jenis pekerjaan $\left(\mathrm{X}_{4}\right)$ sebesar 0.7765 . Hal ini menunjukkan bahwa dalam penelitian mengenai faktor yang mempengaruhi pendapatan keluarga miskin di Kecamatan Maesan Kabupaten Bondowoso, variabel yang berpengaruh adalah variabel pendidikan, variabel usia, dan variabel jumlah tanggungan keluarga yang memiliki pengaruh signifikan terhadap variabel pendapatan. Variabel jenis pekerjaan tidak berpengaruh signifikan terhadap variabel pendapatan.
\end{abstract}

Kata Kunci: Pendapatan, Pendidikan, Usia, Jumlah Tanggungan Keluarga dan Jenis Pekerjan.

\begin{abstract}
This study aims to determine the factors that affect the income of the poorest families in the district Maesan the regency by using the method of analysis Regression (Regression Model Multiplier). Data used in this study are primary data derived from interviews, questionnaire method, the method of observation (cross section) with a research area in District Maesan regency. The regression results obtained from this study indicate that education (X1) and age (X2) has positive effect on revenues. The number of dependents (X3) and the type of work (X4) negative effect on revenue. The probability value of each independent variable is education (X1) of 0.0000 , age (X2) of 0.0000 , the number of dependents (X3) at 0.0000 and the type of work (X4) of 0.7765 . This shows that in the study of factors that affect the income of poor families in the District Maesan Bondowoso, variables that influence the educational variables, variables of age, and a variable number of dependents who have significant influence on the income variable. Variable type of work does not significantly influence the income variable.
\end{abstract}

Keywords: income, education, age, total family dependents and The job type.

\section{Pendahuluan}

Kemiskinan adalah salah satu masalah sosial yang mendasar yang dihadapi oleh Bangsa Indonesia. Hal tersebut ditandai dengan adanya berbagai kekurangan dan ketidakberdayaan diri masyarakat miskin. Berbagai kekurangan dan ketidakberdayaan tersebut disebabkan baik faktor internal maupun eksternal yang dihadapi, seperti adanya keterbatasan untuk memelihara dirinya sendiri, tidak mampu memanfaatkan tenaga fisiknya untuk memenuhi kebutuhannya.Paradigma pembangunan ekonomi Indonesia, khususnya yang berkembang saat ini selalu mengacu pada pertumbuhan ekonomi yang setinggi tingginya. Walaupun dampak dari pertumbuhan ekonomi ini secara teori mampu mengurangi angka kemiskinan, akan tetapi pertumbuhan bukanlah jaminan penuntasan kemiskinan akan menurun. Bahkan pertumbuhan bisa jadi tidak ada kaitannya dengan penurunan angka kemiskinan. Indonesia merupakan negara yang kaya dan memiliki sumber daya alam yang luas, akan tetapi masyarakatnya masih banyak yang miskin. Status sosial ekonomi yang rendah bagi rakyat Indonesia, akibat dari rendahnya kualitas pendidikan sehingga tidak masuk ke lapangan pekerjaan yang menjanjikan untuk mendapatkan penghasilan untuk dapat memenuhi kebutuhan.

Kemiskinan dalam dimensi ekonomi diartikan sebagai kekurangan sumber daya yang digunakan untuk meningkatkan kesejahteraan sekelompok orang, baik secara finansial maupun semua jenis kekayaan yang dapat meningkatkan kesejahteraan masyarakat. Dikategorikan miskin apabila seseorang atau keluarga tidak memenuhi kebutuhan pokok minimnya seperti: sandang, pangan, papan, kesehatan, dan pendidikan. Menurut Ellies (1994), dimensi ekonomi dapat diukur dengan nilai mata uang walaupun harga selalu berubah-ubah setiap tahunnya tergantung pada tingkat inflasi. Kemelaratan dan keterbatasan ini ditentukan oleh kebutuhan hidup yang minimal perlu dipenuhi bagi kehidupan yang sederhana.

Tahun 2012 Jumlah penduduk miskin di Indonesia sebesar 29.132.400 KK (11,96\%). Dibandingkan dengan penduduk

1 Penulis Korespondensi 
miskin pada Maret 2011 yang berjumlah 30.018.930 KK $(12,49 \%)$, berarti jumlah penduduk miskin berkurang 886.530 KK. Jumlah penduduk miskin di daerah perkotaan turun lebih besar daripada daerah pedesaan. Selama periode Maret 2011 - Maret 2012, penduduk miskin di daerah perkotaan berkurang $399.550 \mathrm{KK}$, sementara di daerah pedesaan berkurang 486.980 KK (BPS, 2012).

Kecamatan Maesan memiliki angka keluarga miskin terbesar dibandingkan kecamatan-kecamatan lainnya di Kabupaten Bondowoso. Sebanyak 7.696 KK masih berada dalam kategori keluarga miskin. Karena tingginya angka kemiskinan tersebut maka perlu dilakukan penanggulangan dalam mengentaskan kemiskinan khususnya di Kabupaten Bondowoso.

Penanggulangan kemiskinan dan ketimpangan distribusi pendapatan merupakan masalah pembangunan suatu negara. Salah satu tujuan daripada pembangunan nasional adalah mewujudkan masyarakat yang sejahtera. Pendapatan merupakan salah satu cara dari indikator untuk mewujudkan atau meningkatkan kesejahteraan masyarakat. Untuk itu pendapatan keluarga miskin dapat menjadi kunci dalam memajukan kesejahteraan masyarakat yang merata. Bila pendapatan keluarga miskin bertambah, secara otomatis maka perekonomian suatu daerah pun akan mengalami perubahan yang positif.

Menurut Boediono (1993) pendapatan total (total revenue) adalah total dari semua hasil produksi yang didapat dikalikan dengan harga jual produk yang berlaku atau dengan rumus:

\section{Keterangan:}

$$
\mathbf{T R}=\mathbf{P} \times \mathbf{Q}
$$

$\mathrm{TR}=$ Total Revenue( total pendapatan yang diterima)

$\mathrm{P}=$ Price(harga jual produk)

$\mathrm{Q}=$ Quatitiy (jumlah hasil produk yang dicapai)

Menurut ahli ekonomi klasik pendapatan ditentukan oleh kemampuan faktor-faktor produksi dalam menghasilkan barang dan jasa. Semakin besar kemampuan faktor-faktor produksi dalam menghasilkan barang dan jasa, semakin besar pula pendapatan yang diciptakan. Berdasarkan efektivitas penggunaanya pendapatan bisa saja bergesar seiring dengan pengeluaran yang dikeluarkan oleh masyarakat (Komariyah, 2013)

Berdasarkan uraian tersebut maka peneliti merasa perlu untuk mengkaji lebih jauh tentang faktor-faktor yang mempengaruhi pendapatan keluarga miskin dengan judul "Faktor yang Mempengaruhi Pendapatan Keluarga Miskin di Kecamatan Maesan Kabupaten Bondowoso". Penelitian ini memilih Kecamatan Maesan, Kabupaten Bondowoso, karena Kecamatan Maesan merupakan kecamatan yang memiliki jumlah warga yang memiliki angka kemiskinan tertinggi dibandingkan dengan kecamatan-kecamatan lainnya. Oleh karena itu perlu dilakukan penelitian tentang pendapatan keluarga miskin di daerah ini dan juga variabel-variabel penyebabnya.

\section{Metode}

\section{Jenis Penelitian}

Jenis penelitian ini bersifat descriptive explanatory, karena penelitian ini mempunyai maksud menjelaskan hubungan kausal antara variabel-variabel melalui pengujian hipotesis. Data yang digunakan adalah data primer, dengan menggunakan data cross section yaitu data yang menggambarkan keadaan pada waktu tertentu.

\section{Metode Analisis Data}

Untuk dapat mengetahui pengaruh pendidikan, usia, jumlah tanggungan keluarga dan jenis pekerjaan terhadap pendapatan keluarga miskin di Kecamatan Maesan Kabupaten

Bondowoso, akan digunakan analisis Regresi Linier

Berganda. Sistematis Regresi dapat diformulasikan pada persamaan sebagai berikut:

$$
\mathbf{Y}=\mathbf{b 0}+\mathbf{b}_{1} \mathbf{X}_{1}+\mathbf{b}_{2} \mathbf{X}_{2}+\mathbf{b}_{3} \mathbf{X}_{3}+\mathbf{b}_{4} \mathbf{X}_{4}+\mathbf{e}
$$

\section{Dimana :}

Y :pendapatan;

$\mathrm{b}_{0} \quad$ :besarnya pengaruh pendidikan, umur, jumlah tanggungan keluarga dan jenis pekerjaan terhadap pendapatan sama dengan nol;

$b_{1} \quad$ besarnya pengaruh pendidikan terhadap pendapatan;

$\mathrm{b}_{2} \quad$ :besarnya pengaruh usia terhadap pendapatan;

$\mathrm{b}_{3} \quad$ :besarnya pengaruh jumlah tanggungan keluarga terhadap pendapatan

$\mathrm{b}_{4} \quad$ :besarnya pengaruh jenis pekerjaan terhadap pendapatan

$\mathrm{X}_{1} \quad$ :variabel pendidikan;

$\mathrm{X}_{2} \quad$ :variabel usia;

$\mathrm{X}_{3} \quad$ :variabel jumlah tanggungan keluarga;

$\mathrm{X}_{4} \quad$ :variabel jenis pekerjaan:

$e \quad$ : variabel pengganggu (error terms).

\section{Uji Statistik}

Uji statistik terdiri dari uji pengaruh secara bersama-sama (uji F), uji secara parsial (uji t), dan koefisien determinasi $\left(\mathrm{R}^{2}\right)$.

\section{Uji Asumsi Klasik}

Uji ini merupakan uji terhadap kriteria ekonometrika yang meliputi uji multikolinearitas dan uji heterokedastisitas.

\section{Hasil dan Pembahasan}

\section{Hasil Penelitian}

Analisis regresi dalam penelitian ini dimaksudkan untuk mengetahui besarnya faktor pendidikan $\left(\mathrm{X}_{1}\right)$, usia $\left(\mathrm{X}_{2}\right)$, jumlah tanggungan keluarga $\left(\mathrm{X}_{3}\right)$ dan jenis pekerjaan $\left(\mathrm{X}_{4}\right)$ mempengaruhi pendapatan keluarga miskin di Kecamatan Maesan baik secara parsial maupun secara serentak (bersamasama). Hasil analisis regresi berganda ini diolah dengan menggunakan software eviews 7.

\section{Tabel 1 Hasil Analisis Regresi Linear Berganda}

Dependent Variable: PENDAPATAN

Method: Least Squares

Date: 08/24/16 Time: 07:00

Sample: 1119

Included observations: 119

\begin{tabular}{crrrr} 
Variable & Coefficient & Std. Error & t-Statistic & Prob. \\
\hline C & $\mathbf{5 9 5 6 7 4 . 7}$ & 57460.12 & 10.36675 & 0.0000
\end{tabular}




\begin{tabular}{ccccc} 
PENDIDIKAN & $\mathbf{2 0 7 9 3 . 3 3}$ & 3082.403 & 6.745820 & 0.0000 \\
USIA & $\mathbf{5 1 9 1 . 7 7 3}$ & 1086.602 & 4.777989 & 0.0000 \\
JUMLAH_TANGGUN & & & & \\
GAN_KELUAR & $\mathbf{- 4 1 1 1 6 . 3 2}$ & 4980.246 & -8.255881 & 0.0000 \\
JENIS_PEKERJAAN & $\mathbf{- 5 4 2 0 0 5 8}$ & 19047.28 & -0.284558 & 0.7765 \\
\hline
\end{tabular}

R-squared

0.680510Mean dependent var

753697.5

Adjusted R-squared

0.669299S.D. dependent var

105009.0

S.E. of regression

60387.08 Akaike info criterion

Sum squared resid

Log likelihood

$4.16 \mathrm{E}+11$ Schwarz criterion

-1476.315Hannan-Quinn criter.

60.70456Durbin-Watson stat

0.000000

Sumber: Data diolah

Dari hasil perhitungan regresi linier berganda diatas dalam menganalisis faktor-faktor yang mempengaruhi pendapatan keluarga miskin di Kecamatan Maesan Kabupaten Bondowoso dapat dinyatakan sebagai berikut:

a. Konstanta di Kecamatan Maesan Kabupaten Bondowoso sebesar rasio 595674.7 artinya apabila variabel pendidikan, usia, jumlah tanggungan dan jenis pekerjaan diasumsikan konstan maka diperkirakan rasio jumlah pendapatan di kecamatan Maesan di Kabupaten Bondowoso sebesar Rp595.674,7.

b. Nilai koefisien variabel pendidikan $\left(\mathrm{X}_{1}\right)$ memiliki nilai sebesar 20793.33. Hal ini menunjukkan bahwa setiap kenaikan pendidikan kepala keuarga sebesar 1 tahun jenjang pendidikan, maka akan menaikkan pendapatan kepala keluarga sebesar Rp20.793,33.

c. Koefisien variabel Usia $\left(\mathrm{X}_{3}\right)$ memiliki nilai sebesar 5191.773. Hal tersebut menunjukkan bahwa setiap bertambahnya usia kepala keluarga sebanyak 1 tahun maka akan menaikkan pendapatan sebesar Rp5.191,733.

d. Koefisien variabel Jumlah Tanggungan Keluarga $\left(\mathrm{X}_{3}\right)$ memiliki nilai sebesar -41116.32 . Artinya apabila jumlah tanggungan keluarga bertambah 1 orang, maka akan mengurangi pendapatan kepala keluarga sebesar Rp41.116,32.

e. Koefisien variabel jenis pekerjaan $\left(\mathrm{X}_{4}\right)$ memiliki nilai sebesar -5420.058. Artinya pekerjaan kepala keluarga diluar dari pekerjaan petani, maka akan mengurangi pendapatan sebanyak Rp5.420,058.

\section{Uji Statistik}

\section{Uji F}

Uji $\mathrm{F}$ umtuk mengetahui secara serentak adanya pengaruh pendidikan $\left(\mathrm{X}_{1}\right)$, usia $\left(\mathrm{X}_{2}\right)$, jumlah tanggungan keluarga $\left(\mathrm{X}_{3}\right)$ dan jenis pekerjaan $\left(\mathrm{X}_{4}\right)$ terhadap pendapatan $(\mathrm{Y})$. Kriteria pengambilan keputusan yaitu, bila probabilitas Fhitung $<0,05$ maka $\mathrm{H}_{0}$ ditolak dan Hi diterima yang artinya secara serentak variabel bebas mempunyai pengaruh signifikan terhadap variabel terikat. Bila probabilitas Fhitung $>0,05$ maka $\mathrm{H}_{0}$ diterima dan $\mathrm{H}_{\mathrm{i}}$ ditolak yang artinya secara serentak variabel bebas tidak mempunyai pengaruh signifikan terhadap variabel terikat. Nilai Prob Fhitung $=0.000000$,karena nilai probabilitas Fhitung lebih kecil dari $\alpha=0,05$ maka variabel independen bersama-sama berpengaruh signifikan terhadap variabel dependen.

\section{Uji t}

Uji t dalam analisa ini dimaksudkan untuk mengetahui tingkat signifikansi pengaruh secara parsial antara variabel bebas terhadap variabel terikat. Kriteria pengujian untuk uji $t$ antara

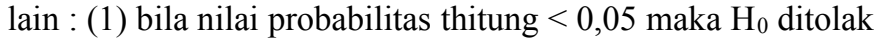
dan $\mathrm{H}_{\mathrm{i}}$ diterima berarti ada pengaruh signifikan antar variabel bebas terhadap variabel terikat; (2) bila nilai probabilitas thitung $>0,05$, maka $\mathrm{H}_{0}$ diterima dan $\mathrm{H}_{0}$ ditolak sehingga tidak ada pengaruh yang signifikan antar masing-masing variabel bebas terhadap variabel terikat.

Dari hasil analisa regresi linier berganda diperoleh data sebagai berikut:

1) Nilai probabilitas pendidikan $\left(X_{1}\right)$ sebesar 0.0000 , lebih kecil dari pada $\alpha=0,05$ maka variabel $\left(X_{1}\right)$ berpengaruh signifikan terhadap variabel Y.

2) Nilai probabilitas Usia $\left(X_{2}\right)$ sebesar 0.0000 , lebih kecil dari pada $\alpha=0,05$ maka variabel $\left(\mathrm{X}_{2}\right)$ berpengaruh signifikan terhadap variabel $\mathrm{Y}$.

3) Nilai probabilitas jumlah tanggungan keluarga $\left(X_{3}\right)$ sebesar 0.0000 , lebih kecil dari pada $\alpha=0,05$ maka variabel $\left(\mathrm{X}_{3}\right)$ berpengaruh signifikan terhadap variabel Y.

4) Nilai probabilitas jenis pekerjaan $\left(X_{4}\right)$ sebesar 0.0000 , lebih besar dari pada $\alpha=0,05$ maka variabel $\left(\mathrm{X}_{4}\right)$ tidak berpengaruh signifikan terhadap variabel $\mathrm{Y}$.

\section{Uji $\mathbf{R}^{2}$}

Uji koefisien determinasi berganda untuk mengukur besarnya sumbangan dari variabel bebas modal, lama usaha, dan jumlah pekerja terhadap variabel terikat yaitu pendapatan. Kriteria pengujian sebagai berikut:

1) Apabila $R^{2}$ mendekati 0, maka tidak ada pengaruh antara variabel bebas terhadap variabel terikat.

2) Apabila $R^{2}$ mendekati 1, maka ada pengaruh antara variabel bebas terhadap variabel terikat.

Besar koefisien determinasi berganda $\left(\mathrm{R}^{2}\right)$ sebesar 0.680510 , hal ini berarti $68,05 \%$ perubahan pendapatan keluarga miskin di Kecamatan Maesan Kabupaten Bondowoso dipengaruhi oleh pendidikan, usia, jumlah tanggungan keluarga dan jenis pekerjaan. Sedangkan $31,95 \%$ disebabkan oleh faktor lain yang tidak termasuk dalam persamaan regresi yang dibuat.

\section{Uji Asumsi Klasik}

\section{Uji Multikolinieritas}

Uji Multikolinieritas adalah pengujian yang dilakukan untuk mengetahui apakah dalam model regresi ditemukan adanya korelasi antar variabel independen. Untuk mendeteksi adanya multikolinieritas maka dapat dilakukan dengan cara menguji koefisien antar variabel independen. Apabila koefisien korelasinya cukup tinggi di atas 0,8 maka diduga model 
tersebut terdapat multikolinieritas. Sebaliknya, apabila koefisien korelasi rendah di bawah 0,8 maka model tersebut tidak terdapat multikolinieritas (Widarjono, 2013:114). Hasil uji multikolineritas bahwa koefisien korelasi antar variabel independen kurang dari 0,8 maka dapat disimpulkan bahwa tidak terdapat masalah multikolineritas dalam setiap variabel independen.

\section{Uji Heterokedastisitas}

Pengujian ini dimaksudkan untuk melihat apakah varian dari gangguan adalah seragam untuk semua observasi. Adanya heterokedastisitas tidak berpengaruh terhadap ketidakbiasan dan konsistensi estimator, tetapi persyaratan varian minimum tidak dapat tercapai sepenuhnya sehingga kurang efisien. Pengujian ini dilakukan dengan menggunakan Uji Glejser (Gujarati, 1995:371). Pengujian heterokedastisitas dilakukan dengan uji glejser yaitu dengan melakukan regresi variabel terikat $\mathrm{Y}$ terhadap semua variabel penjelas $\mathrm{X}$ dengan memperoleh nilai residual dan melakukan regresi dari nilai absolut residual terhadap semua variabel $\mathrm{X}$.

Jika p-value obs* $\mathrm{R}$-squared $<\alpha=0,05$ maka $\mathrm{h}_{0}$ ditolak Nilai probabilitas $\mathrm{Obs}^{*} \mathrm{R}$-squared 0.0000 atau $<$ nilai $\alpha=0,05$ yang artinya $\mathrm{H}_{0}$ di tolak. Artinya terdapat heterokedastisitas dalam model regresi.

\section{Pembahasan}

Penelitian ini menjelaskan ada tidaknya pengaruh hubungan antar variabel yaitu pengaruh pendidikan, usia, jumlah tanggungan keluarga dan jenis pekerjaan terhadap pendapatan keluarga miskin di Kecamatan Maesan Kabupaten Bondowoso. Penelitian ini menggunakan quisoner dan wawancara secara langsung terhadap sampel yang ditentukan yang berjumlah 99 responden yang kemudian ditambah 20 responden untuk memperbaiki model. Diketahui dari hasil analisis regresi linier berganda.

Dalam penelitian ini dilakukan dengan regresi linier berganda, secara bersama-sama (uji f) terdapat pengaruh positif dan signifikan dari model penelitian dan diperjelas melalui hubungan secara struktural setiap variabel.

Berdasarkan hasil analisis uji t dengan menggunakan data primer dapat dijelaskan bahwa variabel pendidikan dengan nilai koefisien variabel sebesar 20793.33 dengan nilai probabilitas 0.0000 berpengaruh positif dan signifikan terhadap pendapatan keluarga miskin di Kecamatan Maesan Kabupaten Bondowoso. Artinya, bahwa jika semakin tinggi tingkat pendidikan maka semakin besar pula pendapatan yang bisa diperoleh oleh keluarga miskin di Kecamatan Maesan Kabupaten Bondowoso.

Dari penelitian di lapangan diketahui bahwa responden yang memiliki pendidikan yang lebih tinggi daripada responden lain lebih terampil sehingga pendapatan yang diperoleh tidak hanya berasal dari pekerjaan utamanya, akan tetapi juga berasal dari pekerjaan sampingan yang menambah jumlah pendapatan kepala keluarga.

Berdasarkan hasil analisis uji t dengan menggunakan data primer dapat dijelaskan bahwa variabel usia dengan nilai koefisien variabel sebesar 5191.773 dengan nilai probabilitas 0.0000 berpengaruh signifikan terhadap pendapatan keluarga miskin di Kecamatan Maesan Kabupaten Bondowoso.
Artinya, bahwa semakin bertambahnya usia seseorang maka akan mempengaruhi tingkat pendapatan yang diperoleh kelurga miskin di Kecamatan Maesan Kabupaten Bondowoso.

Dari hasil penelitian di lapangan terbukti bahwa kepala keluarga yang usianya lebih tinggi memiliki tingkat pendapatan yang lebih tinggi daripada kepala keluarga yang usianya lebih muda. Hal tersebut dikarenakan semakin tinggi usia kepala keluarga, maka ia berusaha untuk menambah tingkat pendapatannya untuk lebih mensejahterakan keluarganya. Dengan bertambahnya usia kepala keluarga akan berpikir bagaimana cara agar menambah pendapatan agar keluarganya dapat terhindar dari lingkaran setan kemiskinan.

Berdasarkan hasil analisis uji t dengan menggunakan data primer dapat dijelaskan bahwa variabel jumlah tanggungan keluarga dengan nilai koefisien variabel sebesar -41116.32 dengan nilai probabilitas 0.0000 berpengaruh negatif dan signifikan terhadap pendapatan keluarga miskin di Kecamatan Maesan Kabupaten Bondowoso. Artinya, bahwa jika semakin banyak jumlah tanggungan keluarga maka semakin besar pula pendapatan yang diperoleh kepala keluarga miskin di Kecamatan Maesan Kabupaten Bondowoso karena berpengaruh negatif.

Hasil penelitian yang dilakukan pada keluarga miskin di Kecamatan Maesan berbeda dengan teori karena dalam keluarga yang memiliki jumlah keluarga yang banyak,anggota keluarga tersebut ikut bekerja untuk membantu perekonomian keluarga sehingga membuat kepala keluarga miskin terbantu yang hasilnya pendapatan kepala keluarga tetap bahkan cenderung berkurang.

Berdasarkan hasil analisis uji $\mathrm{t}$ dengan menggunakan data primer dapat dijelaskan bahwa variabel jenis pekerjaan dengan nilai koefisien variabel sebesar 5420.058 dengan nilai probabilitas 0.7765 , tidak berpengaruh signifikan terhadap pendapatan keluarga miskin di Kecamatan Maesan Kabupaten Bondowoso.Artinya, jenis pekerjaan seseorang tidak akan menentukan besar kecilnya pendapatan seseorang.

Berdasarkan hasil penelitian di lapangan ditemukan bahwa di samping pekerjaan utamanya yang mayoritas petani, responden juga terkadang bekerja mengurus ternak untuk mencari tambahan pekerjaan. Selain kepala keluarga juga terdapat beberapa anggota keluarga yang turut bekerja seperti istri dan anak. Pekerjaan yang dilakukan oleh anggota keluarga lain bersifat membantu untuk konsumsi sehari-hari. Kebanyakan istri yang bekerja sebagai buruh tembakau dan ada pula yang berjualan makanan.

\section{Simpulan}

Berdasarkan hasil dari analisis data dan pembahasan, dapat dikemukakan kesimpulan sebagai berikut:

1. Pendidikan berpengaruh positif dan signifikan terhadap pendapatan keluarga miskin di Kecamatan Maesan Kabupaten Bondowoso

2. Usia berpengaruh positif dan signifikan terhadap pendapatan keluarga miskin di Kecamatan Maesan Kabupaten Bondowoso. 
3. Jumlah tanggungan keluarga berpengaruh negatif dan signifikan terhadap pendapatan keluarga miskin di Kecamatan Maesan Kabupaten Bondowoso.

4. Jenis pekerjaan tidak berpengaruh signifikan terhadap pendapatan keluarga miskin di Kecamatan Maesan Kabupaten Bondowoso.

\section{Saran}

Berdasarkan hasil penelitian yang telah dilakukan tentang faktor yang mempengaruhi pendapatan keluarga miskin di Kecamatan Maesan Kabupaten Bondowoso beberapa saran yang perlu disampaikan sebagai berikut:

1. Tugas pemerintah melalui dinas pendidikan untuk meningkatkan perannya dalam memberikan pendidikan yang layak dan murah bagi masyarakat miskin untuk meningkatkan kualitas pendidikannya, dan juga perlu diadakan peningkatan yang lebih utamanya dalam membantu penyuluhan tentang pendidikan hingga jenjang universitas agak mendapat pendidikan lebih tinggi, serta meningkatkan fasilitas-fasilitas pendidikan secara merata dan tidak terpusat disuatu daerah tetapi merata keseluruh daerah.
2. Masyarakat diharapkan dapat menekan angka kelahiran sekecil mungkin karena semakin banyak jumlah tanggungan keluarga yang ada dalam satu rumah tangga maka akan semakin banyak pengeluaran untuk memenuhi kebutuhan hidupnya. Program KB perlu lebih diintensifkan, masyarakat pedesaan perlu diberikan sosialisasi lebih tentang manfaat dari KB, karena banyak anak belum tentu kesejahteraan mereka terjamin.

\section{Referensi}

Basri, Faisal H. 1998. Perekonomian Indonesia Menjelag Abas XXI, Distorsi, Peluang dan Kendala. Jakarta: Erlangga.

Boediono. 1993. EkonomiMikro. Yogyakarta: BPFE.

Ellies S. 1994. The Dimension of Poverty. Jakarta : Kumarien Press

Gilarso, T. 1992. Pengantar Ekonomi Bagian Makro. Yogyakarta : Kanisius.

Gujarati, 1995. Ekonometrika Dasar. Jakarta : PT Erlangga.

Gujarati, 2003. Basic Econometrics 4 th edition. New York : Mc Graw-Hill.

Komariyah, Ani. 2013. Analisis Beberapa Faktor Yang Mempengaruhi Pendapatan Nelayan :Studi Kasus Di Desa Tembokrejo Kecamatan Muncar Kabupaten Banyuwangi. Jember: UniversitasJember

Simanjuntak, P. 1998: Pengantar Ekonomi Sumber Daya Manusia FEUI.

Sukirno, Sadono. 1992. Pengantar Ekonomi Makro. Jakarta : LPFI-Press.

Widarjono, A.2013. Ekonometrika Teori dan Aplikasi. Yogyakarta: Ekonisia. 